\title{
Uma análise sobre os impactos ambientais de espécies exóticas no Bioma Pampa: da proliferação ao controle necessário das populações de Sus scrofa
}

Taize Dotto Crema

Universidade do Sul de Santa Catarina (Unisul).

E-mail: tdc_28@hotmail.com, http://lattes.cnpq.br/2226550578246626

Jairo Afonso Henkes

Faculdade de Tecnologia AeroTD (AEROTD).

E-mail: jairohenkes333@gmail.com, http://lattes.cnpq.br/6559680I44937II5

ISSN 2448-0479 Submetido em: 21 mai. 2020. Aceito: 05 mar. 202I.

DOI: http://dx.doi.org/10.21674/2448-0479.72.154-164

\section{Resumo}

A espécie Sus scrofa (javali) foi introduzida no Brasil, nos anos de 1904 e 1906, tornando-se uma ameaça à biodiversidade, à economia do setor agrícola e à sociedade. Neste trabalho, foi proposto identificar os impactos ambientais causados na região de Bagé, as ocorrências e danos na agricultura local, assim como o que vem sendo feito para o efetivo controle da espécie. Para obtenção dos resultados, foi realizado um levantamento de dados através de artigos, documentos on-line e instituições locais. Verificou-se que esta situação é originária do manejo realizado no passado, que ocasionou no aumento da população de javalis gerando este desequilíbrio. A proliferação desta espécie tem causado danos ambientais e danos econômicos ao ecossistema local e aos produtores. Nas lavouras de soja, milho, trigo e arroz já se estimaram prejuízos de diferentes montas, chegando a registrar perdas totais em pequenos cultivos. Com estes impactos crescentes, foram necessárias medidas ambientalmente seguras para reorganizar este ecossistema, pois com a ausência de predadores naturais, esta população tende a crescer, sendo necessária a implantação de uma política de controle. Como método de controle populacional, foi identificada a liberação da caça do javali a partir de um Cadastro Técnico Federal e certificação.

Palavras-chave: manejo; crescimento; javali; biodiversidade.

\section{Abstract}

\section{An analysis of the environmental impacts of exotic species in the Pampa Biome: from pro- liferation to the necessary control of Sus scrofa populations}

The species Sus scrofa (wild boar) was introduced in Brazil, during 1904 and 1906, becoming a threat to biodiversity, to agricultural sector economy and to society. In this research, it was proposed to identify environmental impacts caused in the Bagé region, occurrences and damages in local agriculture, as well as what has been done for the species effective control. In order to obtain the results, a data survey was carried out through articles, online documents and local institutions. It was found that this situation originates from management carried out in the past, which caused an increase in the wild boar population, generating this imbalance. The proliferation of this species has caused environmental damage and economic damage to local ecosystem and to producers. In soybean, corn, wheat and rice crops, losses of different amounts have already been estimated, reaching total losses in small crops. With these growing impacts, environmentally safe measures were necessary to reorganize this ecosystem, as with the absence of natural predators this population tends to grow, requiring the implementation of a control policy. As a method of population control, the release of wild boar hunting from a Federal Technical Register and certification was identified.

Keywords: management; growth; boar; biodiversity. 


\section{Resumen \\ Un análisis sobre los impactos ambientales de las especies exóticas en el Bioma Pampa: de la proliferación al control necesario de las poblaciones de Sus scrofa}

La especie Sus scrofa (jabalí) fue introducida en Brasil en los años de 1904 y 1906, convirtiéndose en una amenaza para la biodiversidad, a la economía del sector agrícola y de la sociedad. En este trabajo se propuso identificar los impactos ambientales provocados en la región de Bagé, las ocurrencias y daños en la agricultura local, así como lo que se está haciendo para el efectivo control de la especie. Para la obtención de los resultados, se realizó una encuesta de datos a través de artículos, documentos en línea e instituciones locales. Se verificó que esta situación se origina en el manejo realizado en el pasado, que provocó en el aumento de la población de jabalíes, generando este desequilibrio. La proliferación de esta especie ha causado daños ambientales y económicos al ecosistema local y a los productores. En los cultivos de soya, maíz, trigo y arroz ya se han estimado pérdidas de diferentes cantidades, alcanzando registrar pérdidas totales en cultivos pequeños. Con estos impactos crecientes, fueron necesarias medidas ambientalmente seguras para reorganizar este ecosistema, ya que, con la ausencia de depredadores naturales, esta población tiende a crecer, requiriendo la implementación de una política de control. Como método de control de la población, fue identificada la liberación de la caza de jabalíes a partir de un Registro Técnico Federal y una certificación.

Palabras clave: gestión; crecimiento; jabalí; biodiversidad.

\section{Introdução}

Ao longo dos anos o ser humano vem alterando ciclos da natureza, mesmo com pequenas interferências, quer seja inserindo novas espécies em locais diferentes de seus habitats, quer seja pela eliminação destas em seus locais habituais, com intervenções significativas, obrigando tanto as novas espécies como as já existentes, a se adaptarem às mudanças imprimidas no ecossistema. A alteração na cadeia alimentar destaca-se como um fator importante, pois altera as relações entre os indivíduos, entre presa e predador, e em muitos casos pode não haver um predador para determinada espécie, fazendo com que ela se prolifere sem controle.

O javali (Sus scrofa) é uma das espécies exóticas inserida em biomas distintos ao redor do mundo, sendo que na América do Sul há registros dos primeiros javalis entre os anos de 1904 e 1906 (JAKSIC et al. 2002; MERINO e CARPINETTI, 2003 apud MEDEIROS, 20I3, p. 3). Já no Rio Grande do Sul acredita-se que a sua entrada se deu através da fronteira com o Uruguai em 1989 (FRANKENBERG, 2005; VALÉRIO, 1999 apud MEDEIROS, 20I3, p. 3). "Há também o uso dessa espécie em criadouros, onde houve uma soltura destes animais fazendo com que se tornassem asselvajados" (ICMBIO, 20I8, p. I).

A expansão da espécie em território nacional e os visíveis prejuízos causados à agropecuária, à fauna e à flora, desencadeou a tomada de medidas. Com uma legislação mais específica surgiu a Instrução Normativa $n^{\circ}$. 03, de 31 de janeiro de 2013, que trata sobre a nocividade do javali e o controle da espécie, que foi alterada em 25 de março de 2019, pela Instrução Normativa $n^{\circ}$. 12 que trata da implantação um sistema eletrônico, o Sistema Integrado de Manejo de Fauna - SIMAF, para recebimento de declarações e relatórios de manejo da espécie exótica invasora javali.

Em julho de 2019 foi aprovado o Plano Javali/RS que estabeleceu ações de prevenção, controle e monitoramento da espécie, com o objetivo de conter a expansão da espécie no Rio Grande do Sul e reduzir os seus impactos, oportunidade em que o abate da espécie foi autorizado como forma de controle, sendo, entretanto, necessário o registro e um Certificado de Regularidade junto ao Cadastro Técnico Federal - CTF (SEMA, 2019).

O presente trabalho objetivou analisar os impactos ambientais causados pela espécie Sus scrofa, no Bioma Pampa, em especial na região de Bagé - RS, verificando as informações e ações que vêm sendo desenvolvidas ao longo dos anos na área, com a identificação de possíveis danos causados pela espécie na região de Bagé e no bioma Pampa.

Um Bioma é formado por um grupo de vida animal e vegetal, em determinado local de maneira que a vegetação, a geologia e o clima sejam similares, bem como a sua fauna e flora sejam resultado de um mesmo processo de formação (IBGE, 2019). Por sua vez, o Bioma Pampa, se estende ao longo da América do Sul abrangendo países como Brasil, Uruguai e Argentina, totalizando 750 mil km², composto de uma vegetação de campo em relevo predominantemente de planície, marcado pela presença de grande diversidade de fauna e flora ainda pouco conhecida. 
Fernandes (2017, p. 79) explica que:

No Brasil, o Pampa foi oficialmente reconhecido como bioma apenas em 2004, alcançando status equivalente ao da Mata Atlântica, Pantanal, Cerrado e Amazônia. Até então, era considerado extensão do Bioma Mata Atlântica, fazendo parte dos chamados Campos Sulinos. Seu dia oficial é 17 de dezembro, data escolhida em homenagem ao ambientalista gaúcho José Lutzemberger.

O Brasil, com uma vasta extensão territorial, abrange seis biomas, cada qual caracterizado por sua particularidade e diversidade de fauna e flora. De acordo com o IBGE os biomas brasileiros são: Caatinga, Amazônia, Cerrado, Pantanal, Mata Atlântica e Pampa. O Bioma Pampa cobre uma área de 176.496 km², o que corresponde a cerca de 2,07\% do território brasileiro (IBGE, 2004 apud MMA, 2019, p. I); enquanto que no Rio Grande do Sul corresponde a $63 \%$ do território gaúcho, uma superfície de $176.496 \mathrm{~km}^{2}$, sendo o único bioma brasileiro restrito a apenas um estado (EMBRAPA, 2019). Segundo Sordi; Lewgoy (2017, p. 82),

o Pampa é um bioma campestre, temperado e subtropical, que cobre mais de $750.000 \mathrm{~km}^{2}$ de área no sudeste da América do Sul. Suas planícies férteis e onduladas compreendem as províncias mais orientais da Argentina, a chamada "Metade Sul” do Rio Grande do Sul e a República Oriental do Uruguai - esta última, em toda sua integridade.

O Bioma Pampa é um patrimônio natural, genético e cultural de importância nacional e global (MMA, 2019) sendo considerado o segundo menor bioma do Brasil. A sua diversidade genética vem sendo diretamente afetada ao longo dos anos por ações antrópicas, com a diminuição de uma grande variedade de espécies, que afetam o equilíbrio do meio ambiente em médio e longo prazo.

Para Fiorillo; Diaféria (2012, p. 33) biodiversidade é:

A diversidade da vida, tanto para a existência do planeta como para a sobrevivência do ser humano e este, como foco principal dessa diversidade, hoje - e mais do que em todos os tempos -, é o maior responsável pela sua preservação e pela manutenção da vida para o futuro da humanidade.

O Brasil com características continentais possui um clima que varia de Norte a Sul e uma biodiversidade particular em cada região. Conforme o MMA (2019, p. I), esta abundante variedade de vida coloca o Brasil na lista entre os 17 países classificados como "megadiversos", com mais de $20 \%$ do número total de espécies da Terra. O MMA (2019, p. I) aponta que o "valor da biodiversidade é incalculável" e "sua redução compromete a sustentabilidade do meio ambiente, a disponibilidade de recursos naturais e, assim, a própria vida na Terra", porém "sua conservação e uso sustentável, ao contrário, resultam em incalculáveis benefícios à Humanidade". Essa preocupação não é de hoje, por isso na Constituição Federal do Brasil (1988) em seu Artigo $n^{\circ} .225$ denota-se a afirmativa "todos têm direito ao meio ambiente ecologicamente equilibrado, bem de uso comum do povo e essencial à sadia qualidade de vida, impondo-se ao poder público e à coletividade o dever de defendê-lo e preservá-lo para as presentes e futuras gerações”.

A diversidade biológica encontra-se muitas vezes ameaçada pela inserção de plantas e animais vindos de outros países e até mesmo de outras localidades do Brasil, que quando introduzidas em um ecossistema em harmonia pode trazer desequilíbrio. Fernandes (2017, p. 17) afirma esta observação quando diz que "toda monocultura e inserção de espécies exóticas gera um desequilíbrio ambiental, com a diminuição de algumas espécies e aumento de outras, além de alteração nas funções ecológicas básicas do ecossistema".

O Rio Grande do Sul dispõe de uma grande diversidade em sua fauna, com quase 500 espécies de aves, mais de 100 espécies de mamíferos terrestres e muitas espécies endêmicas (MMA, 2019). As espécies locais vêm enfrentando outras espécies consideradas exóticas que passaram a ocupar um crescente espaço, se tornando uma ameaça à biodiversidade da fauna do bioma pampa.

O termo "espécies exóticas" se refere às espécies que são inseridas ou invadem o habitat de outras, causando um desequilíbrio ambiental e ameaçando a sobrevivência das espécies nativas. O MMA (2006, p. 5) de- 
fine espécies exóticas como "organismos que, introduzidos fora da sua área de distribuição natural, ameaçam ecossistemas, habitats ou outras espécies". Por sua vez, a Comissão Nacional da Biodiversidade - CONABIO (2018, p. 3) discorre sobre a introdução de espécies exóticas como sendo um:

Movimento por ação humana, direta ou indireta, de uma espécie exótica para fora de sua área de distribuição natural (passada ou presente). Esse movimento pode ocorrer dentro de um país ou entre países ou áreas além da jurisdição nacional (CDB, Decisão VI-23).

Um levantamento do MMA (2019) sobre as espécies exóticas no Brasil resultou no Informe Nacional sobre Espécies Exóticas Invasoras. Neste diagnóstico identificou-se um total de 543 espécies, destas 176 foram identificadas como espécies exóticas, que afetam o ambiente terrestre, sendo que 68 delas representam a fauna brasileira. $O$ mesmo estudo cita ainda que a inserção de espécies exóticas pode ser considerada como a segunda maior causa de extinção de espécies no planeta, afetando diretamente a biodiversidade, a economia e a saúde humana.

A proliferação de espécies exóticas tornou-se significativa quando o assunto é impacto ambiental, pois sua inserção pode "gerar híbridos com espécies nativas, colocando-as sob ameaça de extinção" (CONABIO, 2018, p. 3). O IBAMA $(2019$, p. 2) destaca alguns impactos ambientais relacionados à soltura desses animais em biomas que não são os seus de origem:

A morte de diversas espécies nativas da flora e risco à fauna, pois o javali é predador de ovos e filhotes de outras espécies; e, ainda, a transmissão de doenças para os animais nativos, a aceleração do processo de erosão e o aumento do assoreamento dos rios.

No que diz respeito aos impactos sociais e econômicos que espécies exóticas podem causar, com aspectos e impactos como o "ataque a seres humanos e a animais domésticos, dos cruzamentos indevidos com porcos e da destruição de plantações em áreas agrícolas, além da transmissão de doenças para pessoas e para animais de criação" (IBAMA, 20I9, p. 3).

O javali é proveniente da Europa, Ásia e do Norte da África e chegou ao Brasil na década de 1960 com o objetivo de consumo da carne no sul do país. É considerada uma das 100 piores espécies exóticas invasoras e sua agressividade, facilidade de adaptação, reprodução descontrolada e ausência de predadores, causam vários impactos ambientais e socioeconômicos (IBAMA, 2016).

Estudos relatam que a sua entrada em território brasileiro ocorreu pela fronteira do Rio Grande do Sul com o Uruguai. Até o ano de 2016 registrou-se a presença de javalis em 15 unidades da federação: Rio Grande do Sul, Santa Catarina, Paraná, Mato Grosso do Sul, Mato Grosso, Goiás, Distrito Federal, Roraima, Tocantins, Maranhão, Bahia, Minas Gerais, São Paulo, Espírito Santo e Rio de Janeiro (IBAMA, 2016). A figura I, a seguir, ilustra os estados com ocorrência de Javalis.

Figura I: Distribuição da ocorrência de javalis (Sus scrofa) no Brasil

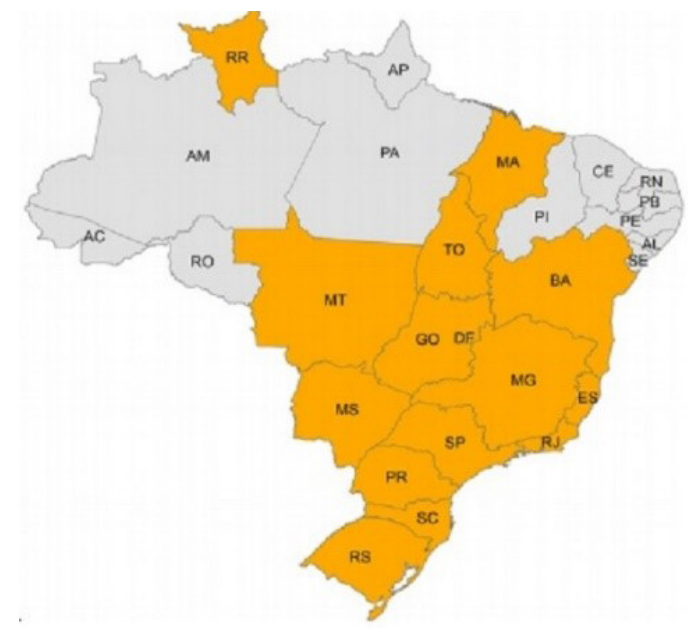

Fonte: Centro de Informação e em Saúde Silvestre - CISS, 2018. 
A falta de um predador natural causa um desequilíbrio no bioma local afetando a vida de outras espécies e de produtores rurais. O IBAMA (2019, p.I), descreve o javali como sendo "um animal com aproximadamente $\mathrm{I}, 3 \mathrm{~m}$ e cerca de $80 \mathrm{~kg}$, aponta ainda que o adulto possui presas e pelos longos de cor preta e que o jovem, além da pelagem preta, apresenta também listras longitudinais marrom avermelhadas. Já os miscigenados com porco doméstico podem chegar a pesar $250 \mathrm{~kg}$ ".

A espécie S. scrofa, em suas mais variadas linhagens e cruzamentos, é considerada um dos animais vertebrados com maior potencial invasor do mundo, o que se explica por sua grande capacidade de adaptação a diferentes ambientes, principalmente por sua dieta onívora e sua alta proliferação (BARRIOS-GARCÍA; BALLARI, 20I2). Os javalis figuram na lista das "I00 piores espécies invasoras do mundo", segundo Lowe et al., (2004) apud Sampaio; Schmidt (2013, p. 37) e consta em um catálogo produzido e atualizado pelo Invasive Species Specialist Group (ISSG), um consórcio de especialistas dedicados a investigar estes problemas que está ligado à União Internacional para a Conservação da Natureza (UICN) (SORDI; LEWGOY, 20I7).

\section{Materiais e Métodos}

\section{Campo de estudo}

Esta pesquisa tem como fundamento ser uma pesquisa exploratória, posto que:

As pesquisas exploratórias têm como principal finalidade desenvolver, esclarecer e modificar conceitos e ideias, tendo em vista a formulação de problemas mais precisos ou hipóteses pesquisáveis para estudos posteriores. Habitualmente envolvem levantamento bibliográfico e documental, entrevistas não padronizadas e estudos de caso. Procedimentos de amostragem e técnicas quantitativas de coleta de dados não são costumeiramente aplicados nestas pesquisas (GIL, 2008, p. 27).

O trabalho também pode ser caracterizado como um estudo de caso, podendo "ser único ou múltiplo e a unidade de análise pode ser um ou mais indivíduos, grupos, organizações, eventos, países ou regiões" (ROES$\mathrm{CH}, 20 \mathrm{I0}$, p. 200). A pesquisa pode ainda ser classificada quanto a sua natureza, sendo utilizado neste estudo o método de pesquisa qualitativa, que possibilita uma maior flexibilidade durante a pesquisa. Silveira; Córdova (2009 apud BARBOSA 2015, p. I8) relatam que:

Os pesquisadores que utilizam os métodos qualitativos buscam explicar o porquê das coisas, exprimindo o que convém ser feito, mas não quantificam os valores e as trocas simbólicas nem se submetem à prova de fatos, pois os dados analisados são não-métricos (suscitados e de interação) e se valem de diferentes abordagens.

A coleta de dados foi realizada através de pesquisas junto aos órgãos locais, tais como a Secretaria de Meio Ambiente e Proteção ao Bioma Pampa (SEMAPA), procurando-se identificar a legislação atual, as normativas e portarias, a identificação de locais de aparições, incidências e estragos causados pela proliferação e de que forma se propõe o controle da espécie $S$. scrofa. A pesquisa documental foi realizada em artigos, documentos on-line, dados de órgãos públicos, tais como: Fepam, Embrapa, Emater, Ibama, ICMBio, IBGE, CONAMA (1986), CONSEMA, entre outros.

\section{Resultados e Discussões}

\section{Ações desenvolvidas ao longo dos anos}

Em junho de 2017 foi instituído o Plano Nacional de Prevenção, Controle e Monitoramento do Javali no Brasil, através da Portaria Interministerial $n^{\circ} .232$ (BRASIL, 2017), que estabeleceu os objetivos gerais para conter a expansão territorial e reduzir os impactos causados pelos javalis, assim como determina ações de prevenção, controle e monitoramento. Para que tais medidas pudessem ser colocadas em prática foi necessário criar também objetivos mais específicos, delimitar ações, prazo de execução, coordenação e monitoria. 
Registre-se de que em março (2019), a Instrução Normativa $n^{\circ}$. 12, criou o Sistema de Informação de Manejo de Fauna (SIMAF), um sistema eletrônico para o recebimento de declarações e relatórios de manejo de espécies exóticas. O SIMAF organiza ainda o controle, perseguição, abate e captura de espécies invasoras, definindo o que e como deve ser feito.

A Secretaria do Meio Ambiente e Infraestrutura (SEMA), criou o Plano Estadual de Prevenção, Controle e Monitoramento do Javali (Sus scrofa) no Estado do Rio Grande do Sul, conhecido também como Plano Javali RS, com o objetivo de "conter a expansão territorial e demográfica do Javali no Rio Grande do Sul, reduzindo seu impacto ambiental e danos sociais e econômicos" (SEMA, 2019). Esse plano iniciou em 2017 e teve o apoio de 25 instituições, para sua implantação foram realizadas oficinas de trabalho com os colaboradores, no intuito de indicar ações que pudessem auxiliar na execução dos objetivos já estabelecidos, com a propositura de 38 ações e destas 19 foram eleitas como prioritárias.

A partir disso, o estado elaborou ainda em 2018, o Programa Estadual de Controle de Espécies Exóticas Invasoras ou Programa Invasoras RS, com a intenção de prevenir que novas espécies exóticas sejam inseridas no estado e que existam formas de controle e monitoramento, em relação às espécies que já estão inseridas (RIO GRANDE DO SUL, 20I8).

\section{Procedimentos legais utilizados para o controle do Sus scrofa}

Existe um sistema disponibilizado no site do IBAMA onde é possível fazer o encaminhamento da documentação necessária para se proceder o manejo de javalis. É um sistema eletrônico conhecido como Sistema de Informação de Manejo de Fauna (SIMAF), que é aplicado também ao manejo de controle de javalis. De acordo com as informações do IBAMA (2019), os procedimentos legais utilizados para o controle dos Javalis seguem os seguintes trâmites:

Inicialmente deve se realizar a inscrição no Cadastro Técnico Federal - CTF. A obrigatoriedade ou não de cadastro vai depender da atividade exercida por cada usuário. Os registros são obrigatórios tanto para pessoa física quanto para pessoa jurídica, com diferenciais em relação ao tipo de atividade desempenhada.

A inscrição é realizada on-line no Site do IBAMA, com a emissão do Certificado de Regularidade no Cadastro Técnico Federal, no qual o lbama atesta que os dados da pessoa inscrita estão em conformidade com as exigências para o Cadastro, atendendo as normativas de controle e fiscalização do IBAMA (IBAMA, 20 I9).

Para acessar ao SIMAF o usuário deve entrar na página https://simaf.ibama.gov.br e fazer Login com o mesmo CPF e senha cadastrados no CTF, escolher a opção "SIMAF - Sistema de Informações de Manejo de Fauna" e cadastrar as propriedades onde serão executas as ações de manejo de controle de javalis; após efetuado este cadastro é possível solicitar a autorização de manejo. Consequentemente, após realizado o cadastro e desenvolvidas as ações, é necessário que sejam enviados os relatórios de manejo, segundo determina o IBAMA (2019, p. 17):

Deverá ser apresentado um relatório para cada propriedade. Pendências relacionadas a não entrega do relatório ocasionarão bloqueios para solicitações de novas autorizações. Relatórios de manejo devem ser entregues regularmente com intervalos máximos de 3 meses vinculados à data final das autorizações a que se referem.

\section{Danos causados ao ecossistema}

Os danos podem ocorrer de um modo geral, tendo em vista que estes animais, quando ameaçados, podem atacar pessoas e animais domésticos nas propriedades rurais. Em alguns casos relatados de invasões destes animais, a agricultura sofreu com a devastação de plantações, sendo devoradas e pisoteadas; já na pecuária, animais podem ser atacados e mortos, levando-se em conta o tamanho e a agressividade dos javalis. Ações danosas como estas podem impactar na economia dos produtores rurais gerando perdas significativas.

O processo de desenvolvimento da população de javalis europeus e seus híbridos no Pampa brasileiro-uruguaio é um caso clássico do que biólogos e ecólogos chamariam de um processo de "invasão biológica", que, por sua vez, ocorre quando "indivíduos de uma espécie não nativa a uma região chegam a ela com assistência humana e estabelecem uma população duradoura" (Simberloff, 2013, p. 2, tradução nossa). Em uma 
análise científica mais aceita, se essa população consegue se proliferar e passa a exercer impactos negativos sobre o ambiente, alterando o ciclo de nutrientes dentro de um ecossistema particular, a espécie é classificada como "espécie exótica invasora" (SORDI; LEWGOY, 20I7).

A fauna e flora local sofrem com o desequilíbrio ambiental trazido por estes animais, que uma vez inseridos buscam se adaptar ao ambiente, gerando transtornos e fazendo com que o bioma local obrigue a se adaptar a esta nova espécie. Outra questão muito importante é a sanitária, pois os javalis podem carregar vírus e infecções. No estado do Rio Grande do Sul há uma precaução em relação a estes animais, pois desde 2015 o estado é livre de Peste Suína Clássica (PSC) de acordo com a Organização Mundial de Saúde Animal (OIE) (SEMA, 20I9).

A biologia das invasões possui diversos instrumentos para modelar o desenvolvimento temporal de invasões biológicas desde o momento em que uma espécie é introduzida em um novo ambiente até seu estabelecimento definitivo junto às demais espécies autóctones (Simberloff, 20I3). Os dados registrados pelo ICMBio, na APA do Ibirapuitã e arredores, revelam o modo como animais penetraram e avançaram sobre o território brasileiro; todavia, pouco informam além do fato do número de avistamentos, ataques à lavouras e à produção animal, que aumentou consideravelmente a partir do ano de 2010 (SORDI; LEWGOY, 2017).

Ainda segundo Bacchetta (2009), em relação ao desequilíbrio ambiental, tanto na fauna quanto na flora, existem razões suficientes para se crer em uma conexão entre a expansão do javali e a expansão dos monocultivos florestais na região. De acordo com suas pesquisas e observações no norte do Uruguai, constatou-se que "todos os vizinhos dos plantios coincidem em afirmar que esse animal se multiplicou e ampliou seus deslocamentos favorecidos por estas condições", porque "tradicionalmente, o javali se abrigava na mata ciliar dos rios e arroios, hoje, os plantios lhe dão proteção porque não há vigilância para evitar isso” (BacchettA, 2009, p. 57).

\section{Ocorrências}

Em nível nacional, dados do Manual de Uso do SIMAF (IBAMA, 2019, p. 4) mostram que existem no país " 563 municípios com registros de javalis (7,5\% de área invadida), abrangendo potencialmente 265 áreas protegidas ( $15,3 \%)$, das quais 4 I Unidades $(2,4 \%)$ já confirmaram a presença da espécie”. Os dados demonstram que desde a implantação de mecanismos de controle, ocorreu uma evolução significativa de aparições, ampliando o mapa de ocorrência que em 2016 relatava a existência de javalis em I5 unidades federativas do Brasil. Em 2019 os registros indicam esta mudança, que podem ser observadas na Figura 2 a seguir, que demonstra em quais estados ocorrem mais registros de presença de javalis no Brasil.

Figura 2: Mapa da percepção do javali no Brasil

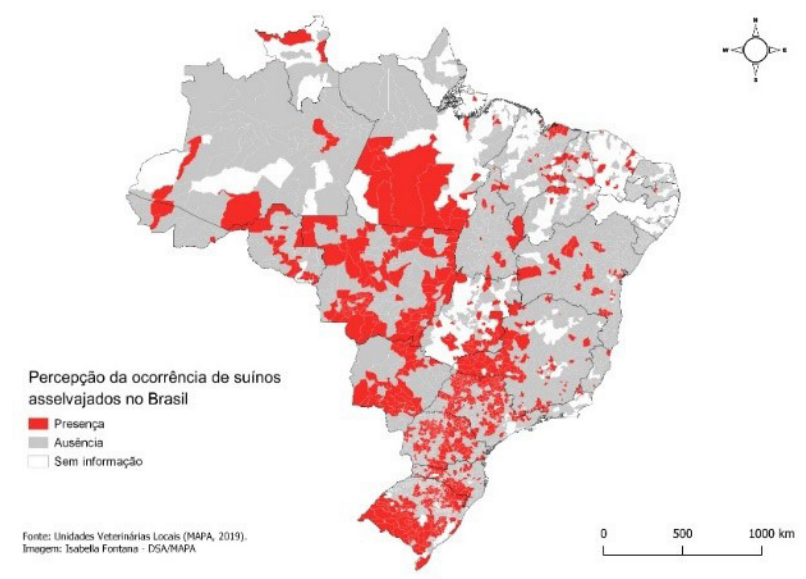

Fonte: SEAPDR, 2019.

Conforme o Boletim Informativo SIMAF/IBAMA (SIMAF, 2019), no período de 04 de abril de 2019 a 30 de setembro de 2019 foram registrados 186 registros de ocorrência de javalis, 2.719 avistados e $66,5 \%$ deles com ataque às lavouras. Durante estes meses foram registrados, respectivamente, I.744, 2.376, 2.379, 2.702, 3.296 e 3.124, totalizando I5.62 I registros de autorizações de controle (SIMAF, 2019). 
Conforme o Boletim Informativo SIMAF/IBAMA (SIMAF, 2019), foram ainda registrados 5.937 relatórios de controle de javalis e 10.882 javalis abatidos; entretanto, as informações obtidas através do Sistema de Informação ao Cidadão, indicam que o SIMAF teria registrado II .483 javalis abatidos no mesmo período. Ainda de acordo com o SIMAF/IBAMA (2019), entre os estados que registraram os maiores números de abates estão Santa Catarina com 2.816, São Paulo com 2.208, seguidos de Minas Gerais, Rio Grande do Sul, Paraná, Mato Grosso do Sul, Goiás, Mato Grosso, Distrito Federal, Rio de Janeiro e Pará, sendo abatidos respectivamente I.760, I.239, I. I45, 872, 693, 107, 13, 12 e II animais autorizados. Observa-se que o estado do Maranhão não se tem registro de abate no período. Utilizando os mesmos dados, foi identificado que dos 10.882 javalis abatidos, $63,2 \%$ eram adultos e apenas $36,8 \%$ juvenis, bem como $55,7 \%$, desse total, eram machos e $44,4 \%$ fêmeas.

De acordo com a Secretaria da Agricultura, Pecuária e Desenvolvimento Rural a Regional - SEAPDR (2019), os municípios do Rio Grande do Sul estão divididos em grupos e estes são classificados como regionais. A $2^{\text {a }}$. Regional é composta por sete municípios: Aceguá, Bagé, Caçapava do Sul, Candiota, Dom Pedrito, Hulha Negra e Lavras do Sul, sendo em Bagé sua sede. A SEAPDR promove cursos de Capacitação em Monitoramento e Vigilância Sanitária de Suídeos Asselvajados, que são desenvolvidos e ministrados pelo Programa de Sanidade Suídea, que serve para habilitar os agentes de acordo com a legislação vigente e normas específicas, fornecendo um Certificado de Regularidade - CR e um Certificado de participação na capacitação.

Os Agentes de manejo recebem kits para que possam fazer a coleta de amostras de sangue ou soro dos javalis e lacres para o transporte dos animais e de acordo com as informações obtidas na $2^{\mathrm{a}}$. Regional Bagé (SEAPDR, 2019), nas cidades de Bagé, Dom Pedrito, Candiota e Caçapava do Sul, existem trinta e quatro agentes de manejo populacional regularizados. Para cada Agente de manejo foram fornecidos 30 lacres, totalizando I.020 lacres entregues; deste total, no momento da coleta de informações para este estudo, já haviam sido utilizados 48 I lacres.

\section{Considerações Finais}

Com base nas informações obtidas foi possível identificar diferenças nas informações e dados entres os órgãos pesquisados, como por exemplo a divergência de informações entre os dados do IBAMA, através do Sistema de Informação ao Cidadão, e as obtidas pelo Boletim Informativo SIMAF/IBAMA, em um mesmo período. Uma proposta de melhoria na comunicação entre estes órgãos locais e nacionais será importante para possibilitar o cruzamento dos dados em um único sistema, para que as informações possam ser atualizadas com a frequência necessária e servirem de base sólida para registrar a realidade em relação aos fatos e orientar novos estudos.

Não se identificou nestes registros, com que frequência os javalis atacam e em quais propriedades rurais, nem tampouco existem números atualizados cotidianamente que demonstrem os prejuízos no setor. Foram analisados os dados registrados pelo IBAMA, através do site Sistema de Informação ao Cidadão, assim como pelo Boletim Informativo disponibilizado pelo SIMAF/IBAMA que são genéricos, os dados regionais e locais foram obtidos através da ${ }^{2}$. Regional da Secretaria da Agricultura, Pecuária e Desenvolvimento Rural, com sede no município de Bagé-RS (SEAPDR, 2019).

Demonstrou-se que os procedimentos de contenção da espécie, como o abate controlado dos javalis, são relativamente novos e os registros realizados nos órgãos competentes ainda carecem de maior precisão, embora sejam fornecidos pelos agentes de manejo capacitados e cadastrados no sistema; no entanto, carecem de resolutividade e objetividade, pois com estes sistemas de registro não foi possível obter dados concretos a respeito de danos e prejuízos quantitativos e qualitativos ocasionados à pecuária e agricultura da região.

Em suma, este trabalho relatou a inserção e evolução da espécie $S$. scrofa nos municípios da $2^{\mathrm{a}}$. Regional da Secretaria da Agricultura, Pecuária e Desenvolvimento Rural do Rio Grande do Sul, a sua proliferação e as formas de controle demandadas e autorizadas pelas autoridades sanitárias e ambientais do país e do estado do Rio Grande do sul.

Ao se analisar a inserção dessa espécie exótica verificou-se pelos registros que houve desequilíbrios na fauna e na flora regionais, com diversos prejuízos para a agricultura e pecuária. Verificou-se ainda que esta situação é originária de um manejo deficiente, tanto de fauna e flora realizados no passado, que ocasionou no aumento da população de javalis e seu cruzamento com espécies suínas nativas, surgindo uma espécie maior. A proliferação desta espécie tem causado danos ambientais e danos econômicos ao ecossistema local e aos 
produtores, com a invasão de pastagens, lavouras e espaços ocupados por outras espécies, originando uma competição com estas normalmente em prejuízo delas.

Nas lavouras de soja, milho, trigo e arroz da região, já se estimaram prejuízos de diferentes montas, chegando a registrar perdas totais em pequenos cultivos. Com estes impactos crescentes, foram necessárias medidas ambientalmente seguras para reorganizar este ecossistema, pois com a ausência de predadores naturais esta população tende a crescer, sendo necessária a implantação de uma política de controle, como por exemplo a autorização de abate como meio de controle da população de javalis.

No entanto, para que o abate seja possível e realizado de forma correta, os agentes de manejo devem participar de um curso e estar regularmente cadastrados na inspetoria de sua cidade. É necessário também que para cada animal abatido, seja dada a baixa no lacre utilizado, assim é possível ter um controle e registro dos abates. Apesar dos esforços para conter a devastação que essa espécie vem causando há uma deficiência quanto aos dados sobre prejuízos causados na agropecuária.

O javali é apenas uma entre tantas espécies invasoras, assim como a rã-touro (Lithobates catesbeianus), o bico-de-lacre (Estrilda astrild), o sagui (Callithrix spp.), a lagartixa-africana (Hemidactylus mabouia), o tigre-d'água (Trachemys scripta elegans), entre outros descritos pela Portaria $n^{\circ} .79$, de 31 de outubro de 2013, disponibilizada pela Secretaria de Meio Ambiente e Infraestrutura do estado do Rio Grande do Sul. A presença e evolução destas e outras espécies citadas pela portaria, deveriam ser melhor investigadas, sendo indicadas como sugestão para pesquisas futuras, pois devido à sua proliferação e expansão se tornam invasoras, podendo apresentar riscos à saúde pública, prejuízos econômicos e ainda perda da biodiversidade.

Salienta-se que ao longo do trabalho houve dificuldade em encontrar bibliografia na área do tema abordado, bem como informações mais localizadas. No entanto, apesar da escassez de materiais relacionados à área, este é um tema relevante a ser estudado.

\section{Referências}

BACCHETTA, V. L. A fraude da celulose. Porto Alegre: Dacasa, 2009.

BARBOSA, Gilvânia. Histórias e memórias de professoras alfabetizadoras do município de Bagé- RS. 2015. 33 f. Monografia (Graduação em Licenciatura em Letras) - Universidade Federal do Pampa, Bagé, 2015.

BARRIOS-GARCÍA, M. N.; BALLARI, S. A. Impact of wild boar (Sus scrofa) in its introduced and native range: a review. Biological Invasions, Dordrecht, v. I4, n. II, p. 2283-2300, 2012. Disponível em: https://link.springer.com/ article/I0.1007/s I0530-0I2-0229-6 Acesso em: 22 set. 2020.

BRASIL. Constituição (1988). Constituição da República Federativa do Brasil. Brasília, DF: Senado Federal, 1988.

Instrução Normativa $\mathbf{n}^{\circ} 12$ de 25 de março de 2019. Fica instituído o Sistema Integrado de Manejo de Fauna - SIMAF, como sistema eletrônico para recebimento de declarações e relatórios de manejo da espécie exótica invasora javali - Sus scrofa. Diário Oficial da União. Brasília, DF, 4 de abr. 2019, Seção I, p.29.

Instrução Normativa $\mathbf{n}^{\circ 3}$ de 31 de janeiro de 2013. Declarar a nocividade da espécie exótica invasora javali-europeu, de nome científico Sus scrofa, em todas as suas formas, linhagens, raças e diferentes graus de cruzamento com o porco doméstico, doravante denominados "javalis". Diário Oficial da União. I de fev. 2013, seção I, p. 88.

Portaria Interministerial n²32 de 28 de junho de 2017. Dispõe sobre o Plano Nacional de Prevenção, Controle e Monitoramento do Javali (Sus scrofa) no Brasil - Plano Javali, estabelecendo seu objetivo geral, objetivos específicos, ações, prazo de execução, coordenação e monitoria. Diário Oficial União. Brasília, DF, 8 nov. 2017, Seção I, p. III.

CISS - Centro de Informação em saúde Silvestre. Boletim Informativo BI - CISS/0 10. 2018. Disponível em:

$<$ https://www.biodiversidade.ciss.fiocruz.br/sites/www.biodiversidade.ciss.fiocruz.br/files/boletim_janeiro2018K. pdf > Acesso em: 09 set. 2019

CONABIO - Comissão Nacional da Biodiversidade. Estratégia nacional para espécies exóticas invasoras. 2018. 
Anexo da Resolução CONABIO n 7, de 29 maio de 2018. Disponível em: <https://www.mma.gov.br/estruturas/conabio/_arquivos/anexo_resoluoconabio05_estrategia_nacional_espcies_invasoras_anexo_resoluoconabio05_15.pdf $>$ Acesso em: 09 set. 2019.

CONAMA - Conselho Nacional do Meio Ambiente (Brasil). RESOLUÇÃO CONAMA n I, de 23 de janeiro de 1986. Publicada no DOU, de 17 de fevereiro de 1986, Seção I, páginas 2548-2549

EMBRAPA - Empresa Brasileira de Pesquisa Agropecuária. (Brasil). Biomas: Pampa. 2019. Disponível em: <https:// www.embrapa.br/web/rede-ilpf/bioma/pampa>. Acesso em: 06 set. 2019.

FERNANDES, Sabrina Oliveira. Paradigmas do Bioma Pampa: aspectos ambientais e atual panorama legal. 2017. I 16 f. Monografia (Especialização em Direito Ambiental Nacional e Internacional)- Universidade Federal do Rio Grande do Sul, Porto Alegre, 2017.

FIORILLO, Celso Antonio Pacheco; DIAFÉRIA, Adriana. Biodiversidade, patrimônio genético e biotecnologia no Direito Ambiental. $2^{a}$ edição. São Paulo: Saraiva, 2012.

GIL, Antonio Carlos. Método e técnicas de pesquisa social. $6^{\mathrm{a}}$ ed. São Paulo: Atlas, 2008.

IBAMA - Instituto Brasileiro do Meio Ambiente e dos Recursos Naturais Renováveis. Manejo e controle do javali. 2016. Disponível em: <http://ibama.gov.br/index.php?option=com_content\&view=article\&id=546>. Acesso em: 27 ago. 2019.

Grupo de Trabalho Do Bioma Pampa. O Zoneamento Ambiental da Atividade da Silvicultura no Rio Grande do Sul. Parecer da Equipe Técnica do Ibama. Disponível em: < https://pt.calameo.com/read/0000735904laf3a24b953>. Acesso em 08 set. 2019.

O Javali Asselvajado: norma e medidas de controle. Disponível em: < http://www.ibama.gov.br/phocadownload/biodiversidade/javali/ibama-cartilha-javali_asselvajado.pdf $>$ Acesso em: 09 set. 2019.

Manual de uso do sistema de Monitoramento de Fauna (Simaf) aplicado ao manejo de javalis. Juliana Junqueira e Graziele Oliveira Batista, Organizadoras. Brasília: Ibama, 2019.

IBGE - INSTITUTO BRASILEIRO DE GEOGRAFIA E ESTATÍSTICA (Brasil). Biomas Brasileiros. 20I9. Disponível em: <https://teen.ibge.gov.br/images/teen/mapas/2017_07_I4_mapa-biomas.pdf >. Acesso em: 05 set. 2019.

ICMBIO. Instituto Chico Mendes de Conservação da Biodiversidade. Lançado Guia para Produtor Rural de Controle de Javalis. 10 de maio de 2018. Disponível em: < http://www.icmbio.gov.br/portal/ultimas-noticias/20-geral/ 96।7-icmbio-lanca-guia-para-produtor-rural-de-controle-de-javalis $>$. Acesso em 20 nov. 2019.

MEDEIROS, Antonio Augusto Rosa. Importância de Estabelecimento de um Sistema de Vigilância Sanitária nas Populações de Javalis Asselvajados no Rio Grande do Sul. 2013. Informativo Técnico N 04/Ano 04 - abri I de 20I3. Disponível em: <https://www.agricultura.rs.gov.br/upload/arquivos/201612/02101332-inftec-38-importancia-de-estab-de-sistema-de-vigilancia-sanitaria-de-javalis-no-rs.pdf >. Acesso em: 28 ago. 2019.

MMA. Ministério do Meio Ambiente. Espécies Exóticas Invasoras: Situação brasileira. Secretaria de Biodiversidade e Florestas. - Brasília: MMA, 2006. 24 p. Disponível em: <https://www.mma.gov.br/estruturas/I74/_publicacao/I74 publicacao I 7092009| |3400.pdf >. Acesso em: 09 set. 2019.

Pampa: Conhecimentos e descobertas. 2019. Disponível em: < https://www.mma.gov.br/images/imagens/biomas/pampa/pampa_conhecimentos_e_descobertas_frente.jpg >. Acesso em: 06 set. 2019.

Biodiversidade brasileira. 2019b. Disponível em: <https://www.mma.gov.br/biodiversidade/biodiversidade-brasileira >. Acesso em: 08 set. 2019.

RIO GRANDE DO SUL. Portaria conjunta SEMA/FEPAM n 14 de maio de 20 I8. Cria o Programa Estadual de Controle de Espécies Exóticas Invasoras - Invasoras RS, a Unidade de Gerenciamento, institui a rede de colaboradores, e dá outras providências. Diário Oficial. Porto Alegre, RS, 29 mai. 2018, p. 204. 
ROESCH, Sylvia Maria Azevedo. Projetos de Estágio e de Pesquisa em Administração: Guia para Estágios, TrabaIhos de Conclusão, Dissertações e Estudos de Caso. 3 ed. v.6. São Paulo: Atlas, 2010.

SAMPAIO, A. B.; SCHMIDT, I. B. . Espécies Exóticas Invasoras em Unidades de Conservação Federais do Brasil. Biodiversidade Brasileira, v. 3, p. 32-49, 2013. Disponível em: http:/quintalflorestal.com.br/wp-content/uploads/2017/05/ Especies-Exoticas-e-Invasoras-em-Unidades-de-Conservacao-Federais-no-Brasilpdf.pdf Acesso: 20 out. 2019.

SEAPDR. Secretaria da Agricultura, Pecuária e Desenvolvimento Rural a Regional. Endereços de Regionais e IDA's. Disponível em: <https://www.agricultura.rs.gov.br/enderecos-de-regionais-e-ida-s>. Acesso em: 18 nov. 2019

SEMA. Secretaria do Meio Ambiente e Infraestrutura. Plano Estadual de Prevenção, Controle e Monitoramento do javali (Sus scrofa) no Estado do Rio Grande do Sul. 2019. Disponível em: < https://www.sema.rs.gov.br/upload/ arquivos/201907/17162820-plano-javali-rs.pdf> Acesso em: 18 nov. 2019.

Secretaria da Agricultura e Meio Ambiente. Secretarias da Agricultura e do Meio Ambiente se unem para controlar expansão do javali no Estado. (2019). Disponível em:https://www.estado.rs.gov.br/secretarias-da-agricultura-e-meio-ambiente-se-unem-para-controlar-expansao-do-javali-no-estado. Acesso em: 12 out. 2019.

Secretaria do Meio Ambiente e Infraestrutura. Portaria SEMA n 79 de 3 I de outubro de 20 I3. Reconhece a Lista de Espécies Exóticas Invasoras do Estado do Rio Grande do Sul e demais classificações, estabelece normas de controle e dá outras providências. I nov. 2013.

SIMAF. Boletim Informativo SIMAF/IBAMA. 2019. Disponível em: <https://simaf.ibama.gov.br/boletins/boletim I4. pdf $>$. Acesso em 30 out. 2019.

SIMBERLOFF, D. Invasive species: what everyone needs to know. Oxford: Oxford University Press, 2013.

SORDI, Caetano; LEWGOY, Bernardo. Javalis no Pampa: invasões biológicas, abigeato e transformações da paisagem na fronteira brasileiro-uruguaia. Revista Horizontes Antropológicos. n 48, 2017. p 75-98. Disponível em: <https:// journals.openedition.org/horizontes/ I 586> Acesso em: 22 set .2020. 